\title{
The role of gender in non-small cell lung cancer: a narrative review
}

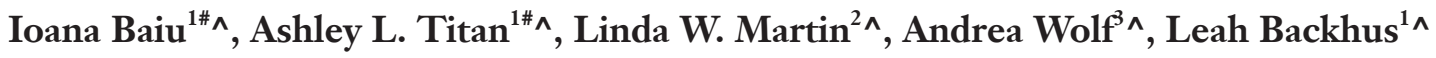 \\ ${ }^{1}$ Department of Surgery, Stanford University Hospital, Stanford, CA, USA; ${ }^{2}$ Thoracic and Cardiovascular Surgery, University of Virginia, \\ Charlottesville, Virginia, USA; ${ }^{3}$ Department of Surgery, Mount Sinai Hospital, New York, NY, USA \\ Contributions: (I) Conception and design: All authors; (II) Administrative support: I Baiu, AL Titan; (III) Provision of study materials or patients: I \\ Baiu, AL Titan; (IV) Collection and assembly of data: I Baiu, AL Titan; (V) Data analysis and interpretation: All authors; (VI) Manuscript writing: All \\ authors; (VII) Final approval of manuscript: All authors. \\ \#These authors contributed equally to this work. \\ Correspondence to: Leah Backhus. Stanford University, Stanford, CA, USA. Email: lbackhus@stanford.edu.
}

\begin{abstract}
The role of gender in the development, treatment and prognosis of thoracic malignancies has been underappreciated and understudied. While most research has been grounded in tobacco-related malignancies, the incidence of non-smoking related lung cancer is on the rise and disproportionately affecting women. Recent research studies have unveiled critical differences between men and women with regard to risk factors, timeliness of diagnosis, incongruent screening practices, molecular and genetic mechanisms, as well as response to treatment and survival. These studies also highlight the increasingly recognized need for targeted therapies that account for variations in the response and complications as a function of gender. Similarly, screening recommendations continue to evolve as the role of gender is starting to be ellucidated. As women have been underrepresented in clinical trials until recently, the data regarding optimal care and outcomes is still lagging behind. Understanding the underlying similarities and differences between men and women is paramount to providing adequate care and prognostication to patients of either gender. This review provides an overview of the critical role that gender plays in the care of patients with non-small cell lung cancer and other thoracic malignancies, with an emphasis on the need for increased awareness and further research to continue elucidating these disparities.
\end{abstract}

Keywords: Gender; women; lung cancer; esophageal cancer

Submitted Oct 23, 2020. Accepted for publication Apr 12, 2021.

doi: $10.21037 /$ jtd-20-3128

View this article at: http://dx.doi.org/10.21037/jtd-20-3128

\section{Introduction}

\section{Does gender matter?}

Over three decades ago, the National Institutes of Health (NIH) established the Office of Research on Women's Health, imposing stringent restrictions on the inclusion of women in research studies on the basis of presumed and unforeseen harm to women of child-bearing age. In 1993, the NIH Revitalization Act required inclusion of women in their funded trials, but it was not until October 2014 that a formal policy was established requiring a balanced approach to gender analysis in research studies (1). As a result, knowledge regarding gender-differences in oncologic diseases is severely lagging. Numerous studies published since have analyzed the role of gender in development and prognosis for various cancers, however very little attention

^ ORCID: Ioana Baiu, 0000-0003-3541-0846; Ashley Titan, 0000-0003-2711-7172; Linda Martin, 0000-0002-7951-5677; Andrea Wolf, 0000-0003-1256-1780; Leah Backhus, 0000-0002-4553-1003. 
has been focused on thoracic malignancies. Non-small cell lung cancer (NSCLC) continues to be the most common thoracic malignancy and the leading cause of cancer-related deaths in both men and women in the United States and worldwide (2-4). Despite this, NSCLC is being increasingly recognized as a heterogenous disease in which gender plays a critical, and much bigger, role than previously appreciated in pathogenesis, diagnosis and treatment. The complex interactions between biological factors, hormonal differences, environmental and occupational exposures, are just starting to be identified, and there is an increasing awareness of the importance of gender in thoracic malignancies. This manuscript provides a review on the role that gender plays in the diagnosis, treatment and outcomes of patients with thoracic malignancies, focusing on NSCLC. We present the following article in accordance with the Narrative Review Reporting Checklist (available at: http://dx.doi.org/10.21037/jtd-20-3128).

\section{Materials and methods}

An extensive PubMed database research was performed looking specifically at the role of gender and thoracic malignancies. We used the following search terms and their combinations: "thoracic malignancy", "lung cancer", "NSCLC", "esophageal cancer", "mesothelioma", "surgery", "chemotherapy", "radiotherapy", "clinical trials", "gender", "women" and "sex". Following the initial search, additional articles retrieved from cited references were included. Only original articles published after the year 2000 were included to provide a more contemporary review of recent knowledge. Conference abstracts, articles without full text or manuscripts not in English were excluded.

\section{Cancer risk}

\section{Smoking and non-small cell lung cancer}

The link between tobacco and NSCLC has been clearly established. As a result of cultural and geographical differences in smoking trends, women have been underrepresented in research studies. This has led not only to a paucity of available data for female patients, but, when included, it also overestimates the survival statistics in men who, when analyzed separately, have an overall worse prognosis (5). Women's survival is higher than men's, despite being more susceptible to the effects of tobacco (6-9). In the last few decades, the rate of smoking in women has increased, an epidemic that has likely not yet reached its peak, particularly in developing countries (10). Although the impact of e-cigarettes is not yet fully characterized, studies show that there are gender-specific differences regarding reasons behind initiation and maintenance of smoking $(7,11,12)$. Tobacco companies have also intensified targeted advertising, especially as more women are entering the workforce and becoming financially independent. They emphasize menthol cigarettes, which are associated with higher levels of cotinine (by-product of nicotine), which has been related to higher nicotine exposure and associated with more severe addiction (13). In a recent study utilizing the North American Association of Central Cancer Registries, among 30-50 year old non-Hispanic whites, the femaleto-male incidence ratio of tobacco-related lung cancer has increased from 0.88 (95\% CI: $0.84-0.92)$ in $1995-1999$ to 1.17 (95\% CI: 1.11-1.23) in 2010-2014 (14). This partially explains why the rates of smoking related lung cancer are not decreasing as steeply in women as they are in their male counterparts. The reasons behind smoking also appear to be influenced by gender; for example, fear of weight gain disincentivizes women from quitting, but is not considered as important to men (15). Following smoking cessation, the annual risk reduction is $8 \%$ for adenocarcinoma and $17 \%$ for squamous-cell carcinoma (16). Since women are more affected by adenocarcinoma, the overall lung cancer risk reduction following smoking cessation is not as pronounced in this group $(14,17)$. However, tobacco use does not explain everything (18). Identifying gender differences beyond tobacco use can guide targeted social interventions, treatment and support programs.

\section{Non-smoking risk factors for lung cancer}

Over the last couple of decades, the incidence of lung cancer among non-smokers has been steadily increasing and disproportionately affecting women more than men (14.4 to 20.8 per 100,000 person-years compared to 4.8 to 13.7 per 100,000 person-years respectively) (19). As more female patients are included in research studies, several other important differences between genders have been unveiled among non-smokers (20). For example, hazardous exposures in the environment and workplace can vary by gender. Occupational exposures such as construction-related asbestos significantly increase the risk of mesothelioma and lung cancer in men (21). Industrial pollution, radon gas in mines, and arsenic have synergistic effects with smoking and historically increased risk of lung cancer mostly in men (15). 
As these identifiable exposures decreased over the years, the decline in lung cancer in men has been steeper than in women.

Environmental exposures specifically impacting women have been less well-studied. For example, secondary exposures to chemicals present in men's clothing could account for some of the risk. High-temperature cooking (e.g., wok), aerosolization of carcinogens or volatile oils have also been implicated in the development of lung cancer among non-smoking Chinese women (22). The role that hormone replacement therapy plays in NSCLC development and progression remains controversial; a recent secondary analysis of the Prostate, Lung, Colorectal, and Ovarian (PLCO) Cancer Screening Trial found that estrogen is associated with a reduced incidence of NSCLC particularly in female smokers (4). Although outdoor pollution is not expected to differentially affect men $v s$. women, no one has investigated this topic. Another area that has not been investigated is the role of talc, mica, silica and other nanoparticles present in powder that are aerosolized and inhaled primarily by women who use cosmetics. The exposure to residential radon, which is known to be associated with the development of NSCLC, varies based upon the location of one's home and socioeconomic status; since traditionally women have been more likely to be home-makers, their exposure is presumably increased, yet no studies have investigated gender differences $(23,24)$.

\section{Gender differences in prognosis of lung cancer}

While female gender imparts a significant and independent risk for the development of most types of lung cancer (20), numerous studies have shown that men actually have lower overall survival and disease-free survival regardless of histology, stage or treatment (25-29). These findings have been consistent for lung cancer as well as malignant pleural mesothelioma. A meta-analysis of pooled hazard ratios of 86,800 patients revealed higher survival for women with non-small-cell lung cancer (NSCLC) in both univariate and multivariate analyses (HR 0.78, $\mathrm{P}<0.0001)(25)$, and multiple other reports show female gender to be a predictor of improved survival in multivariate analyses of patients with lung adenocarcinoma (30).

\section{Other thoracic malignancies}

Although not the focus of this narrative, gender has also been implicated in other thoracic malignancies.
For example, while the incidence of malignant pleural mesothelioma is lower in women, survival is significantly higher, particularly for young women (21,31). Esophageal cancer remains a male-dominant disease and less is known about the role of gender influences on its clinical course (32). Men are six to eight times more likely to develop adenocarcinoma of the esophagus, and slightly more likely to develop squamous cell carcinoma, compared to women (33). Reflux esophagitis is a predisposing risk factor for esophageal cancer, and there appears to be a strong and dose-dependent association with body mass index in women, but not in men; however, it is not clear if this necessarily translates to a higher risk of cancer $(34,35)$. Moreover, gender has been shown in some studies to be an independent prognostic factor in esophageal cancer. Specifically, women have a higher 5- and 10-year survival as well as metastasis-free survival, which is partially attributed to diagnosis at an earlier stage compared to men (36-38). Indeed, esophageal adenocarcinoma is one of the main cancers contributing to the increasing rate of death among men in the United States (39). Overall, the literature regarding thoracic malignancie other than lung cancer is somewhat limited at the time of this review. This is not to say that gender does not play a role, but rather that it has not yet been specifically investigated as a primary predictor of cancer incidence.

\section{Screening and diagnosis}

\section{Lung cancer}

Although the medical community has become more cognizant of gender differences in thoracic malignancies, the general public's awareness is lagging behind. A population survey of over 2,026 adults in the U.S. revealed that only $6 \%$ of responders knew that lung cancer is the primary cause of cancer death in women. Screening for breast and colon cancer have been widely publicized in the media, but lung cancer screening has not yet reached such proportions. Following the 2011 National Lung Cancer Screening Trial (NLST) and the 2018 Dutch-Belgian Randomized Lung Cancer Screening (NELSON) trials, the U.S. Preventive Services Task Force (USPSTF) now recommends annual screening for lung cancer with low-dose chest CT (LDCT) for adults ages 55-80 years with a 30 pack-year smoking history who are current smokers or quit within the past 15 years (40-42). This was just updated in 2020, expanding to $50-80$ years of age with 20 pack-year smoking 
history (43). The newest version of USPSTF guidelines (pending publication at the time of this manuscript) have lowered the age and smoking exposure requirements to meet screening criteria (44). The change is expected to double the number of eligible individuals, and will hopefully benefit all of those potentially at risk, particularly the younger females with less smoking exposure.

Despite being large, these above studies focus on highrisk populations, whereas non-smokers and women are considered low risk. There are currently no established recommendations for screening non-smoking women despite the disproportionately high incidence of lung cancer among female never-smokers, because it is difficult to justify the added screening effort in the absence of strong data that better define the predisposing risk factors in this population.

Even among patients identified as high risk, it has been a challenge to broadly implement screening. A study analyzing national database registries from 2016 found that only $1.9 \%$ of 7.6 million eligible smokers were screened (45). Although smoking intensity is a part of lung cancer screening guidelines, eligibility for screening does not take in to account sex-based differences in lung cancer risk; women tend to start smoking at an older age and smoke less intensively than men (46). Given that in the last decade the rate of diagnosis of lung cancer in nonsmokers has doubled (47), and that non-smoking women are disproportionately affected, the current guidelines are already outdated. Furthermore, they do not account for non-tobacco related exposures (aerosolized cooking oils, prior malignancy, emphysema and recurrent pneumonia, second hand smoke), some of which disproportionately affect women more than men (18). Family history of lung cancer is also strongly associated with adenocarcinoma, early age of onset, and female gender, however is not included in the screening guidelines (48). A study based in a NSCLC endemic area of Taiwan looking at 1,075 Asian patients, found that family history of lung cancer and female gender were the two most important predictors of lung cancer (OR 11.2 and OR 2.8 respectively) (49). Overall, there has been a decline in the proportion of patients who meet USPSTF criteria, from $56.8 \%$ in $1984-1990$ to $43.3 \%$ in 2005-2011 $(\mathrm{P}<0.001)(50)$. Notably, the decline is much more pronounced in women $(52.3 \%$ to $36.6 \%, \mathrm{P}<0.05)$ compared to men $(60.0 \%$ to $49.7 \%, \mathrm{P}=0.03)$.

To answer the question of whether never-smoker women benefit from LDCT, a 2018 Korean retrospective study of 4,365 subjects aged 40-79 found that after 9.7-year followup $22(0.5 \%)$ of women had lung cancer. Out of these new diagnoses, 73\% were Lung Imaging Reporting and Data System (Lung-RADS) category 4. The authors argued that the risk of lung cancer in never-smoking women was sufficiently low that repeat annual LDCT screening is not necessary for at least 5 years if the initial screen was LungRADS 1-3 (51). Similarly, a group from Taiwan applied the NLST criteria to a population 1,763 subjects ages $40-80$, 1,029 men and 734 women. Low-dose CT was indicated in $8.4 \%$ of these patients using the NLST guidelines, but only one patient would have been diagnosed with lung cancer using these criteria. Among the 1,615 patients who did not meet criteria for screening, the detection rate of lung cancer was $2.6 \%$ in women and $0.56 \%$ in men. These data illustrate that the National Lung Cancer Screening criteria might not apply to women in the same way as they do to men. A study analyzing CT screening of lung cancer in North America found the prevalence of lung cancer to be significantly higher in women compared to men of similar age and smoking history (odds ratio 1.9, 95\% CI: 1.5-2.5) (9). Given that women have higher survival rates compared to men, it raises the question of whether the tumors detected through screening or diagnostic imaging are more indolent in females. Presently, there are more young women than young men diagnosed with lung cancer, particularly among 30-49 years old, a group that, irrespective of smoking status, does not typically meet screening criteria (14). The mean preclinical sojourn (i.e., the preclinical duration in the absence of screening of each stage of cancer) is higher for women (3.35-6 years) than for men (3.09-5.32 years), and most pronounced in adenocarcinoma (52). This study suggests a greater window of opportunity for screening, particularly among patients with adenocarcinoma and women.

In the absence of screening, another potential contributor to delay in diagnosis is lower levels of helpseeking behavior for early symptoms of lung cancer (e.g., cough, hoarseness) among smokers, which differ between the sexes (53). Gender differences have also been observed with respect to referral to care; a study in malignant pleural effusions (including, but not limited, to lung cancer) suggested that women have a lower referral rate for definitive care (54). To minimize delays in diagnosis, screening efforts must be accompanied by efforts to educate the public about early diagnosis methods. In order to direct these tools appropriately, current epidemiologic trends must be studied in conjunction with predictive models for future changes to the population at risk in order to mount a timely response to shifts in incidence and prevalence of lung cancer. This, 
in turn, requires a deeper understanding of the cultural and social norms associated with initiation of smoking and other exposures, as well as the stigma associated with a new diagnosis, all of which have been shown in the literature to differ among men and women (15).

\section{Other thoracic malignancies}

Early detection of esophageal cancer is associated with improved outcomes. Women tend to be younger at presentation, diagnosed at an earlier stage, possibly due to lower frequencies of cigarette smoking and alcohol consumption compared to men (38). Although screening methods for esophageal cancer exist, they have not demonstrated feasibility or cost effectiveness in prospective studies due to relatively low incidence of this disease (36-39). The lack of a known hereditary link also makes population-wide screening techniques less practical for patients with family history of esophageal cancer. There are well established screening guidelines for esophageal cancer in patients with Barrett's esophagus and/or symptoms of gastroesophageal reflux disease (GERD). However, the adherence to these guidelines is variable, and similar to lung cancer, worse for women compared to men patients (55).

\section{Medical therapy}

\section{Lung cancer}

One of the critical discoveries in the treatment of lung cancer in the last decade has been the identification of genderdifferences in tumor biology and response to therapy. Gender-specific pharmacology, particularly with regard to the role of estrogen receptors, is expected to be part of future chemotherapy regimens for thoracic malignancies. The treatment modalities are anecdotally different between genders. For example, one study of over 200,000 patients using the SEER database from 1975-1999 suggests that men were more likely to receive radiotherapy as a first line treatment, while women more likely to undergo surgery, although this difference alone does not explain the higher survival in women (56). These differences, however, may be attributable to treatment practices that are outdated. Multiple molecular and genetic differences have been identified between men and women and implicated in both susceptibility to lung cancer and treatment response (57). For example, activating mutations in the tyrosine kinase domain of EGFR are more common in in women compared to men ( $20 \%$ vs. $9 \%$, respectively). Furthermore, EGFR mutations are more common in Asian women and non-smokers (63\% of cases in Asian female non-smokers) $(58,59)$. Early studies on Tyrosine kinase inhibitors such as gefitinib and erlotinib, which prevent activation of EGFR, lead to a survival benefit only among women, non-smokers, patients with adenocarcinoma, and Japanese patients (57). More recently, in a double blinded phase 3 trial, the use of Osimertinib in patients with EGFR-positive Stage IIA-Stage IIIB non-small cell lung cancer had a significantly improved disease free survival (60). Another example is the improved clinical response in men with the addition of bevacizumab to carboplatin/ paclitaxel therapy (ECOG E4599 study, $\mathrm{P}<0.0001)$. The lack of benefit in women may be explained by potential interactions of EGFR inhibitors with bevacizumab (57). The first clinical study to evaluate gender differences in tumor biology is the PIONEER randomized controlled trial in women with advanced NSCLC and ECOG performance status 2 (61). Paclitaxel poliglumex (PPX) as a single agent or in combination with carboplatin was been evaluated in phase II trials and showed no benefit in men, but increased survival in women. The proposed mechanism for this difference is the modulation of efficacy through estrogen receptors. The ongoing phase III trial is investigating the use of PPX as a single agent against paclitaxel in women only.

Beyond differences in response to therapy, gender also plays a role in the incidence of side effects, delays in treatment and doses of chemotherapy. Several trials have noted increased side effects as nausea, vomiting, alopecia, neurosensory toxicity, severe hypertension, constipation, abdominal pain in women compared to men (30). All of this suggests a need for gender-specific pharmacologic treatments. Finally, there are no studies investigating fertility problems in women who develop thoracic malignancies at a young age. As lung cancer is increasingly being diagnosed in younger patients, there are no data available to inform decisions regarding treatment options and fertility.

Radiation therapy has also been associated with differential outcomes based on gender, although the data is more limited than for other treatment modalities. In particular, a prospective study of stereotactic body radiotherapy (SBRT) in NSCLC concluded that women had improved survival than men $(80.3 \%$ vs. $51.3 \%$ at 3 years, $\mathrm{P}=0.008$ ), although the authors could not elucidate if this was due to gender alone or the fact that adenocarcinoma 
was more prevalent in women who already have an improved survival compared to their male counterparts (62). In a different study, gender has been identified as an independent predictor of survival in patients treated with SBRT for early stage NSCLC, suggesting that indeed gender may influence outcomes regardless of histology (63).

\section{Other thoracic malignancies}

A recent review of clinical trials in esophageal cancer revealed a remarkable lost opportunity for inquiry as 23 out of 30 the studies included did not analyze female and male patients separately; despite this, gender differences in response to chemotherapy and radiation were apparent (64). The study quantifies the tremendous paucity of data regarding sex-specific therapies for esophageal cancer. One such study that did investigate gender differences found that, sex has been shown to be an independent prognostic factor in large cohort study investigating esophageal squamous cell carcinoma who underwent definitive radiotherapy; women had a better survival compared to men, yet the underlying etiology for this remains unknown (65).

\section{Surgical care}

\section{Lung cancer}

Surgical resection is generally considered the standard of care for the majority of early-stage NSCLC, and used in combination with chemotherapy, radiation, molecularly targeted therapy, and immunotherapy for more advanced disease. Despite this, it has been repeatedly reported that women undergo appropriate surgical intervention for NSCLC at lower rates compared to men $(66,67)$. In a study utilizing the Surveillance, Epidemiology, and End Results Program data, women were found to be $25 \%$ less likely to receive timely lung resection as compared to men (68). Women are also more likely to undergo a more limited surgical resection compared to men $(69,70)$. There is certainly a role for limited sublobar resection for stage I NSCLC and for patients with significant comorbidities or limited pulmonary function which make them medically unfit for lobectomy. However, the fact that there is a difference in the type of surgical resection as a function of gender is alarming. Furthermore, women with advanced disease (Stage III/IV) have been shown to have a lower a likelihood to receive referrals to cancer care (including thoracic Women had significantly lower rates of postoperative cardiovascular and pulmonary complications and overall post-operative survival in women, surgeons) compared to their male counterparts (71).

The differences in the likelihood of the recommendation of surgical resection to surgical candidates based on gender has been shown to be at least partly related to physician bias (67). In a survey of over 100 cardiothoracic trainees and attending surgeons, estimation of complication risk was independently associated with the gender of the physician and the patient, thereby influencing the likelihood of recommending an operation for reasons unrelated to age, indication, and/or comorbidities of the patient (67). The dearth of research in gender-differences in surgery for thoracic malignancies represents an unmet need (72).

Of the women who do undergo surgical resection for lung cancer, only a handful of studies have investigated differences in perioperative and postoperative outcomes between men and women. An STS General Thoracic Database study demonstrated that women had lower inhospital and 30-day mortality (O.R. 0.56, 95\% CI: $0.44-$ $0.71 ; \mathrm{P}<0.001)(70)$. Women had significantly lower rates of postoperative cardiovascular and pulmonary complications and overall post-operative survival in women, however it is important to note that men did have a higher pathological stage (70). Others have shown that women had shorter lengths of stay post-operatively (73). The specific reasons for these differences have not been studied, but hormonal, inflammatory, and additional immunologic factors, and societal influences may play a role.

Female gender has been associated with increased pain and narcotic use after various procedures, however less clearly for lung cancer operations. In a study investigating 1,164 patients (601 of which were female), no difference was seen in perioperative pain levels between men and women who underwent minimally invasive surgery (74). A smaller study investigating 157 patients who underwent resection via a major thoracotomy (62 of which were female) reported that women had significantly greater pain in the perioperative setting as well as following discharge (75). With these mixed findings, additional research is needed to identify if different approaches to postoperative pain management for men compared to women is warranted.

There have also been mixed findings for data regarding the risk for postoperative readmissions for women versus men. A single institution study found that women had significantly more unplanned readmissions within 30 days 
of discharge after having lung cancer resection $(67 \% v s$. $36 \%, \mathrm{P}=0.038)$, despite having a similar amount of ED admissions within the first 30 days of discharge (12\% vs. $10 \%, \mathrm{P}=0.531$ ), indicating there are differences not only in treatment planning ,but also in the short-term postoperative period (76). This may in part be due to the fact that women and men have different postoperative symptom experiences (76-78). However, other large database studies have demonstrated men were more likely to be readmitted than women after being discharged from the index operation (4.9\% versus $3.8 \%, \mathrm{P}<0.001$ ) (79). Although the data is unclear as to which gender is more likely to be readmitted, efforts to optimize readiness for discharge, provide education about expectations post-discharge, resources for questions and concerns, can help prevent unplanned readmissions following thoracic oncological resections for both genders.

\section{Clinical trials and health research}

Prospective clinical trials are the standard for evaluating clinical interventions and advancing medicine. It has been reported that the majority (84\%) of participants in NCI-sponsored surgical oncology trials are women (80). However, this statistic is a gross overestimate as a result of the enormous number of women included in surgical oncology studies for breast cancer such as the NSABP B-32, ACOSOG Z10, and Z11 trials. In stark contrast, women are significantly underrepresented in lung cancer trials (80).

Substantial knowledge gaps remain because of a continued lack of inclusion of women especially those who are in childbearing age or pregnant despite recent research policy changes expanding inclusion criteria. Given the known molecular, hormonal, and immunologic differences between men and women, which may lead to different response to specific pharmacological agents, gender must be evaluated further in clinical trials. Examples include differential effect of EGFR-specific tyrosine kinase inhibitors favoring women and in anti-PD1 checkpoint inhibitors, favoring men (26).

Several recent studies have focused specifically on women and gender differences in lung and esophageal cancer $(26,81)$. Another evaluated 354 female patients with mesothelioma to identify female specific disease trends (82). There is a great need for similar studies for all thoracic malignancies to drive hypothesis development for important prospective clinical trials.

\section{Summary}

Gender plays a critical role in thoracic malignancies, not only in terms of risk factors, but also for diagnosis, treatment and outcomes. As oncologic care is advancing toward individualized approaches to patient care and personalized pharmacotherapy, the need for further research is more urgent than ever given the unexplained and increasing incidence of cancer in non-smokers and women. Furthermore, as gender-based differences are slowly starting to be elucidated, there is a dire need for advocacy and increased awareness for screening and early detection of thoracic malignancies, which are continuing to be the primary cause of death from cancer in both men and women.

\section{Acknowledgments}

Funding: None.

\section{Footnote}

Provenance and Peer Review: This article was commissioned by the Guest Editors (Virginia Litle and Kei Suzuki) for the series "Socioeconomic Disparities in the Treatment of Thoracic Malignancies" published in Journal of Thoracic Disease. The article has undergone external peer review.

Reporting Checklist: The authors have completed the Narrative Review Reporting Checklist. Available at: http:// dx.doi.org/10.21037/jtd-20-3128

Peer Review File: Available at http://dx.doi.org/10.21037/jtd20-3128

Conflicts of Interest: All authors have completed the ICMJE uniform disclosure form (available at http://dx.doi. org/10.21037/jtd-20-3128). The series "Socioeconomic Disparities in the Treatment of Thoracic Malignancies" was commissioned by the editorial office without any funding or sponsorship. The authors have no other conflicts of interest to declare.

Ethical Statement: The authors are accountable for all aspects of the work in ensuring that questions related to the accuracy or integrity of any part of the work are appropriately investigated and resolved. 
Open Access Statement: This is an Open Access article distributed in accordance with the Creative Commons Attribution-NonCommercial-NoDerivs 4.0 International License (CC BY-NC-ND 4.0), which permits the noncommercial replication and distribution of the article with the strict proviso that no changes or edits are made and the original work is properly cited (including links to both the formal publication through the relevant DOI and the license). See: https://creativecommons.org/licenses/by-nc-nd/4.0/.

\section{References}

1. Clayton JA, Collins FS. Policy: NIH to balance sex in cell and animal studies. Nature 2014;509:282-3.

2. World Health Organization. Cancer. [cited 2010 Aug 31]. Available online: https://www.who.int/news-room/factsheets/detail/cancer.

3. Bray F, Ferlay J, Soerjomataram I, et al. Global cancer statistics 2018: GLOBOCAN estimates of incidence and mortality worldwide for 36 cancers in 185 countries. CA Cancer J Clin 2018;68:394-424.

4. Titan AL, He H, Lui N, et al. The influence of hormone replacement therapy on lung cancer incidence and mortality. J Thorac Cardiovasc Surg 2020;159:15461556.e4.

5. Rivera MP, Stover DE. Gender and lung cancer. Clin Chest Med 2004;25:391-400.

6. De Matteis S, Consonni D, Pesatori AC, et al. Are women who smoke at higher risk for lung cancer than men who smoke? Am J Epidemiol 2013;177:601-12.

7. Yu Y, Liu H, Zheng S, et al. Gender susceptibility for cigarette smoking-attributable lung cancer: A systematic review and meta-analysis. Lung Cancer 2014;85:351-60.

8. O'Keeffe LM, Taylor G, Huxley RR, et al. Smoking as a risk factor for lung cancer in women and men: a systematic review and meta-analysis. BMJ Open 2018;8:e021611.

9. International Early Lung Cancer Action Program Investigators, Henschke CI, Yip R, Miettinen OS. Women's Susceptibility to Tobacco Carcinogens and Survival After Diagnosis of Lung Cancer. JAMA 2006;296:180-4.

10. Neugut AI, Jacobson JS. Women and Lung Cancer: Gender Equality at a Crossroad? JAMA 2006;296:218.

11. Perikleous EP, Steiropoulos P, Paraskakis E, et al. E-Cigarette Use Among Adolescents: An Overview of the Literature and Future Perspectives. Front Public Health 2018;6:86.
12. Piñeiro B, Correa JB, Simmons VN, et al. Gender differences in use and expectancies of e-cigarettes: Online survey results. Addict Behav 2016;52:91-7.

13. Benowitz NL, Hukkanen J, Jacob P. Nicotine Chemistry, Metabolism, Kinetics and Biomarkers. Handb Exp Pharmacol 2009;(192):29-60.

14. Jemal A, Miller KD, Ma J, et al. Higher Lung Cancer Incidence in Young Women Than Young Men in the United States. N Engl J Med 2018;378:1999-2009.

15. Isla D, Majem M, Viñolas N, et al. A consensus statement on the gender perspective in lung cancer. Clin Transl Oncol 2017;19:527-35.

16. Kenfield SA, Wei EK, Stampfer MJ, et al. Comparison of aspects of smoking among the four histological types of lung cancer. Tobacco Control 2008;17:198-204.

17. Lewis DR, Check DP, Caporaso NE, et al. US lung cancer trends by histologic type: US Lung Cancer Trends by Histologic Type. Cancer 2014;120:2883-92.

18. Kligerman S, White C. Epidemiology of lung cancer in women: risk factors, survival, and screening. AJR Am J Roentgenol 2011;196:287-95.

19. Wakelee HA, Chang ET, Gomez SL, et al. Lung cancer incidence in never smokers. J Clin Oncol 2007;25:472-8.

20. Gasperino J, Rom WN. Gender and Lung Cancer. Clin Lung Cancer 2004;5:353-9.

21. Wolf AS, Richards WG, Tilleman TR, et al. Characteristics of malignant pleural mesothelioma in women. Ann Thorac Surg 2010;90:949-56.

22. Sisti J, Boffetta P. What proportion of lung cancer in never-smokers can be attributed to known risk factors? Int J Cancer 2012;131:265-75.

23. Bogen KT, Cullen J. Residential Radon in U.S. Counties V Lung Cancer in Women Who Predominantly Never Smoked. Environmental Geochemistry and Health 2002;24:229-47.

24. Kendall GM, Miles JCH, Rees D, et al. Variation with socioeconomic status of indoor radon levels in Great Britain: The less affluent have less radon. J Environ Radioact 2016;164:84-90.

25. Nakamura H, Ando K, Shinmyo T, et al. Female gender is an independent prognostic factor in non-small-cell lung cancer: a meta-analysis. Ann Thorac Cardiovasc Surg 2011;17:469-80.

26. Pinto JA, Vallejos CS, Raez LE, et al. Gender and outcomes in non-small cell lung cancer: an old prognostic variable comes back for targeted therapy and immunotherapy? ESMO Open 2018;3:e000344. 
27. Visbal AL, Williams BA, Nichols FC, et al. Gender differences in non-small-cell lung cancer survival: an analysis of 4,618 patients diagnosed between 1997 and 2002. Ann Thorac Surg 2004;78:209-15.

28. LaPar DJ, Bhamidipati CM, Harris DA, et al. Gender, Race, and Socioeconomic Status Affects Outcomes After Lung Cancer Resections in the United States. Ann Thorac Surg 2011;92:434-9.

29. Thomas L, Doyle LA, Edelman MJ. Lung cancer in women: emerging differences in epidemiology, biology, and therapy. Chest 2005;128:370-81.

30. Harichand-Herdt S, Ramalingam SS. Gender-Associated Differences in Lung Cancer: Clinical Characteristics and Treatment Outcomes in Women. Semin Oncol 2009;36:572-80.

31. Taioli E, Wolf AS, Camacho-Rivera M, et al. Women with malignant pleural mesothelioma have a threefold better survival rate than men. Ann Thorac Surg 2014;98:1020-4.

32. Abbas G, Krasna M. Overview of esophageal cancer. Ann Cardiothorac Surg 2017;6:131-6.

33. Eslick GD. Epidemiology of Esophageal Cancer. Gastroenterol Clin North Am 2009;38:17-25.

34. Kamangar F, Chow WH, Abnet CC, et al. Environmental causes of esophageal cancer. Gastroenterol Clin North Am 2009;38:27-57, vii.

35. Nilsson M, Lundegårdh G, Carling L, et al. Body Mass and Reflux Oesophagitis: an Oestrogen-dependent Association? Scand J Gastroenterol 2002;37:626-30.

36. Koide N, Kitazawa M, Komatsu D, et al. Gender differences in clinicopathologic features and outcomes of esophageal cancer patients treated surgically. Esophagus 2011;8:107-12.

37. Morita M, Otsu H, Kawano H, et al. Gender differences in prognosis after esophagectomy for esophageal cancer. Surg Today 2014;44:505-12.

38. Rohatgi PR, Correa AM, Swisher SG, et al. Genderbased analysis of esophageal cancer patients undergoing preoperative chemoradiation: differences in presentation and therapy outcome. Dis Esophagus 2006;19:152-7.

39. Zhang Y. Epidemiology of esophageal cancer. World J Gastroenterol 2013;19:5598-606.

40. Ma J, Ward EM, Smith R, et al. Annual number of lung cancer deaths potentially avertable by screening in the United States. Cancer 2013;119:1381-5.

41. Yousaf-Khan U, van der Aalst C, de Jong PA, et al. Risk stratification based on screening history: the NELSON lung cancer screening study. Thorax 2017;72:819-24.

42. Moyer VA. Screening for Lung Cancer: U.S. Preventive
Services Task Force Recommendation Statement. 2014

Mar. Ann Intern Med 2014;160:330-8.

43. Draft Recommendation: Lung Cancer: Screening I United States Preventive Services Taskforce. [cited 2020 Oct 5]. Available online: https://www. uspreventiveservicestaskforce.org/uspstf/draftrecommendation/lung-cancer-screening-2020.

44. U.S. Preventive Services Task Force. [cited 2020 Sep 20]. Available online: https://www. uspreventiveservicestaskforce.org/uspstf/draft-updatesummary/lung-cancer-screening-2020.

45. Pham D, Bhandari S, Oechsli M, et al. Lung cancer screening rates: Data from the lung cancer screening registry. J Clin Oncol 2018;36:6504.

46. Rivera MP, Katki HA, Tanner NT, et al. Addressing Disparities in Lung Cancer Screening Eligibility and Healthcare Access. An Official American Thoracic Society Statement. Am J Respir Crit Care Med 2020;202:e95-112.

47. Cufari ME, Proli C, De Sousa P, et al. Increasing frequency of non-smoking lung cancer: Presentation of patients with early disease to a tertiary institution in the UK. Eur J Cancer 2017;84:55-9.

48. Wu AH, Fontham ETH, Reynolds P, et al. Family History of Cancer and Risk of Lung Cancer among Lifetime Nonsmoking Women in the United States. Am J Epidemiol 1996;143:535-42.

49. Lin KF, Wu HF, Huang WC, et al. Propensity score analysis of lung cancer risk in a population with high prevalence of non-smoking related lung cancer. BMC Pulm Med 2017;17:120.

50. Wang Y, Midthun DE, Wampfler JA, et al. Trends in the proportion of patients with lung cancer meeting screening criteria. JAMA 2015;313:853-5.

51. Kim HY, Jung KW, Lim KY, et al. Lung Cancer Screening with Low-Dose CT in Female Never Smokers: Retrospective Cohort Study with Long-term National Data Follow-up. Cancer Res Treat 2018;50:748-56.

52. Ten Haaf K, van Rosmalen J, de Koning HJ. Lung Cancer Detectability by Test, Histology, Stage, and Gender: Estimates from the NLST and the PLCO Trials. Cancer Epidemiol Biomarkers Prev 2015;24:154-61.

53. Friedemann Smith C, Whitaker KL, Winstanley K, et al. Smokers are less likely than non-smokers to seek help for a lung cancer 'alarm' symptom. Thorax 2016;71:659-61.

54. Foote DC, Burke CR, Pandian B, et al. Gender Disparity in Referral for Definitive Care of Malignant Pleural Effusions. J Surg Res 2019;244:409-16.

55. Holmberg D, Ness-Jensen E, Mattsson F, et al. Adherence 
to clinical guidelines for Barrett's esophagus. Scand J Gastroenterol 2019;54:945-52.

56. Fu JB, Kau TY, Severson RK, et al. Lung Cancer in Women. Chest 2005;127:768-77.

57. Belani CP. Adjuvant and neoadjuvant therapy in non-small cell lung cancer. Semin Oncol 2005;32:S9-15.

58. Chapman AM, Sun KY, Ruestow P, et al. Lung cancer mutation profile of EGFR, ALK, and KRAS: Metaanalysis and comparison of never and ever smokers. Lung Cancer 2016;102:122-34.

59. Ha SY, Choi SJ, Cho JH, et al. Lung cancer in neversmoker Asian females is driven by oncogenic mutations, most often involving EGFR. Oncotarget 2015;6:5465-74.

60. Wu YL, Tsuboi M, He J, et al. Osimertinib in Resected EGFR-Mutated Non-Small-Cell Lung Cancer. N Engl J Med 2020;383:1711-23.

61. Albain KS, Belani CP, Bonomi P, et al. PIONEER: A Phase III Randomized Trial of Paclitaxel Poliglumex Versus Paclitaxel in Chemotherapy-Naive Women with Advanced-Stage Non-Small-Cell Lung Cancer and Performance Status of 2. Clin Lung Cancer 2006;7:417-9.

62. Matsuo Y, Shibuya K, Nagata Y, et al. Prognostic Factors in Stereotactic Body Radiotherapy for NonSmall-Cell Lung Cancer. Int J Radiat Oncol Biol Phys 2011;79:1104-11.

63. Koshy M, Malik R, Weichselbaum RR, et al. Increasing Radiation Therapy Dose Is Associated With Improved Survival in Patients Undergoing Stereotactic Body Radiation Therapy for Stage I Non-Small-Cell Lung Cancer. Int J Radiat Oncol Biol Phys 2015;91:344-50.

64. Liu F, Feng H, Guo S, et al. Esophageal Cancer: Should Gender Be Considered as an Influential Factor for Patient Safety in Drug Treatment? J Oncol 2019;2019:6340567.

65. Luo HS, Xu HY, Du ZS, et al. Impact of sex on the prognosis of patients with esophageal squamous cell cancer underwent definitive radiotherapy: a propensity scorematched analysis. Radiat Oncol 2019;14:74.

66. Jazieh AR, Kyasa MJ, Sethuraman G, et al. Disparities in surgical resection of early-stage non-small cell lung cancer. J Thorac Cardiovasc Surg 2002;123:1173-6.

67. Ferguson MK, Huisingh-Scheetz M, Thompson K, et al. The Influence of Physician and Patient Gender on Risk Assessment for Lung Cancer Resection. Ann Thorac Surg 2017;104:284-9.

68. Shugarman LR, Mack K, Sorbero MES, et al. Race and sex differences in the receipt of timely and appropriate lung cancer treatment. Med Care 2009;47:774-81.

69. Balekian AA, Wisnivesky JP, Gould MK. Surgical Disparities Among Patients With Stage I Lung Cancer in the National Lung Screening Trial. Chest 2019;155:44-52.

70. Tong BC, Kosinski AS, Burfeind WR, et al. Sex differences in early outcomes after lung cancer resection: Analysis of the Society of Thoracic Surgeons General Thoracic Database. J Thorac Cardiovasc Surg 2014;148:13-8.

71. Goulart BHL, Reyes CM, Fedorenko CR, et al. Referral and treatment patterns among patients with stages III and IV non-small-cell lung cancer. J Oncol Pract 2013;9:42-50.

72. Blom EF, Ten Haaf K, Arenberg DA, et al. Disparities in Receiving Guideline-Concordant Treatment for Lung Cancer in the United States. Ann Am Thorac Soc 2020;17:186-94.

73. Wright CD, Gaissert HA, Grab JD, et al. Predictors of Prolonged Length of Stay after Lobectomy for Lung Cancer: A Society of Thoracic Surgeons General Thoracic Surgery Database Risk-Adjustment Model. Ann Thorac Surg 2008;85:1857-65.

74. Sun K, Liu D, Chen J, et al. Moderate-severe postoperative pain in patients undergoing video-assisted thoracoscopic surgery: A retrospective study. Sci Rep 2020;10:795.

75. Ochroch EA, Gottschalk A, Augostides J, et al. Longterm Pain and Activity during Recovery from Major Thoracotomy Using Thoracic Epidural Analgesia. Anesthesiology 2002;97:1234-44.

76. Nelson DB, Lapid DJ, Mitchell KG, et al. Perioperative Outcomes for Stage I Non-Small Cell Lung Cancer: Differences Between Men and Women. Ann Thorac Surg 2018;106:1499-503.

77. Oksholm T, Rustoen T, Cooper B, et al. Trajectories of Symptom Occurrence and Severity From Before Through Five Months After Lung Cancer Surgery. J Pain Symptom Manage 2015;49:995-1015.

78. Zimmerman L, Barnason S, Hertzog M, et al. Gender differences in recovery outcomes after an early recovery symptom management intervention. Heart Lung 2011;40:429-39.

79. Medbery RL, Gillespie TW, Liu Y, et al. Socioeconomic Factors Are Associated With Readmission After Lobectomy for Early Stage Lung Cancer. Ann Thorac Surg 2016;102:1660-7.

80. Stewart JH, Bertoni AG, Staten JL, et al. Participation in Surgical Oncology Clinical Trials: Gender-, Race/ Ethnicity-, and Age-based Disparities. Ann Surg Oncol 
2007;14:3328-34.

81. Hsu LH, Chu NM, Kao SH. Estrogen, Estrogen Receptor and Lung Cancer. Int J Mol Sci 2017;18:1713.

Cite this article as: Baiu I, Titan AL, Martin LW, Wolf A, Backhus L. The role of gender in non-small cell lung cancer: a narrative review. J Thorac Dis 2021;13(6):3816-3826. doi: $10.21037 /$ jtd-20-3128
82. Pavlisko EN, Liu B, Green C, et al. Malignant Diffuse Mesothelioma in Women: A Study of 354 Cases. Am J Surg Pathol 2020;44:293-304. 